JAMA | US Preventive Services Task Force | RECOMMENDATION STATEMENT

\title{
Screening for Hepatitis B Virus Infection in Pregnant Women
} US Preventive Services Task Force Reaffirmation Recommendation Statement

US Preventive Services Task Force

IMPORTANCE Screening for hepatitis B virus (HBV) infection during pregnancy identifies women whose infants are at risk of perinatal transmission. Data from a nationally representative sample showed a prevalence of maternal HBV infection of 85.8 cases per 100000 deliveries from 1998 to 2011 (0.09\% of live-born singleton deliveries in the United States). Although there are guidelines for universal infant $\mathrm{HBV}$ vaccination, rates of maternal $\mathrm{HBV}$ infection have increased annually by $5.5 \%$ since 1998 . Children infected with HBV during infancy or childhood are more likely to develop chronic infection. Chronic HBV infection increases long-term morbidity and mortality by predisposing infected persons to cirrhosis of the liver and liver cancer.

OBJECTIVE To update the 2009 US Preventive Services Task Force (USPSTF) recommendation on screening for $\mathrm{HBV}$ infection in pregnant women.

EVIDENCE REVIEW The USPSTF commissioned a reaffirmation evidence update to identify substantial new evidence sufficient enough to change the prior recommendation. The USPSTF targeted its evidence review on the effectiveness and potential harms of screening and the effectiveness and harms of case management to prevent perinatal transmission.

FINDINGS The USPSTF previously found adequate evidence that serologic testing for hepatitis B surface antigen accurately identifies HBV infection. Interventions are effective for preventing perinatal transmission, based on foundational evidence and observational studies of US case management programs. In addition, there is evidence that over time, perinatal transmission has decreased among women and infants enrolled in case management, providing an overall substantial health benefit. Therefore, the USPSTF reaffirms its previous conclusion that there is convincing evidence that screening for $\mathrm{HBV}$ infection in pregnant women provides substantial benefit.

CONCLUSIONS AND RECOMMENDATION The USPSTF recommends screening for HBV infection in pregnant women at their first prenatal visit. (A recommendation)

JAMA. 2019;322(4):349-354. doi:10.1001/jama.2019.9365

Corrected on September 17, 2019.

\author{
$\leftarrow$ Edit \\ $+$ \\ ditorial page 312 \\ Author Audio Interview \\ Related article page 360 and \\ JAMA Patient Page page 376 \\ CME Quiz at \\ jamanetwork.com/learning
}

Author/Group Information: The US Preventive Services Task Force (USPSTF) members are listed at the end of this article.

Corresponding Author: Douglas K. Owens, MD, MS, Stanford University, 616 Serra St, Encina Hall, Room C336, Stanford, CA 94305-6019 (chair@uspstf.net).
$\mathrm{T}$ he US Preventive Services Task Force (USPSTF) makes recommendations about the effectiveness of specific clinical preventive services for patients without obvious related signs or symptoms.

It bases its recommendations on the evidence of both the benefits and harms of the service and an assessment of the balance. The USPSTF does not consider the costs of providing a service in this assessment.

The USPSTF recognizes that clinical decisions involve more considerations than evidence alone. Clinicians should understand the evidence but individualize decision making to the specific patient or situation. Similarly, the USPSTF notes that policy and coverage decisions involve considerations in addition to the evidence of clinical benefits and harms.

\section{Summary of Recommendation and Evidence}

The USPSTF recommends screening for hepatitis B virus (HBV) infection in pregnant women at their first prenatal visit (A recommendation) (Figure 1).

\section{Rationale}

Importance

Screening for HBV infection during pregnancy identifies women whose infants are at risk of perinatal transmission. Data from a nationally representative sample showed a prevalence of maternal 


\begin{tabular}{|c|c|c|}
\hline \multicolumn{3}{|c|}{ What the USPSTF Grades Mean and Suggestions for Practice } \\
\hline Grade & Definition & Suggestions for Practice \\
\hline A & The USPSTF recommends the service. There is high certainty that the net benefit is substantial. & Offer or provide this service. \\
\hline B & $\begin{array}{l}\text { The USPSTF recommends the service. There is high certainty that the net benefit is moderate, or } \\
\text { there is moderate certainty that the net benefit is moderate to substantial. }\end{array}$ & Offer or provide this service. \\
\hline C & $\begin{array}{l}\text { The USPSTF recommends selectively offering or providing this service to individual patients } \\
\text { based on professional judgment and patient preferences. There is at least moderate certainty } \\
\text { that the net benefit is small. }\end{array}$ & $\begin{array}{l}\text { Offer or provide this service for selected } \\
\text { patients depending on individual } \\
\text { circumstances. }\end{array}$ \\
\hline D & $\begin{array}{l}\text { The USPSTF recommends against the service. There is moderate or high certainty that the service } \\
\text { has no net benefit or that the harms outweigh the benefits. }\end{array}$ & Discourage the use of this service. \\
\hline I statement & $\begin{array}{l}\text { The USPSTF concludes that the current evidence is insufficient to assess the balance of benefits } \\
\text { and harms of the service. Evidence is lacking, of poor quality, or conflicting, and the balance of } \\
\text { benefits and harms cannot be determined. }\end{array}$ & $\begin{array}{l}\text { Read the Clinical Considerations section } \\
\text { of the USPSTF Recommendation } \\
\text { Statement. If the service is offered, } \\
\text { patients should understand the } \\
\text { uncertainty about the balance of benefits } \\
\text { and harms. }\end{array}$ \\
\hline
\end{tabular}

USPSTF Levels of Certainty Regarding Net Benefit

\begin{tabular}{||l|l||}
\hline Level of Certainty & Description \\
\hline High & $\begin{array}{l}\text { The available evidence usually includes consistent results from well-designed, well-conducted studies in representative primary care } \\
\text { populations. These studies assess the effects of the preventive service on health outcomes. This conclusion is therefore unlikely to be } \\
\text { strongly affected by the results of future studies. }\end{array}$ \\
\hline Moderate & $\begin{array}{l}\text { The available evidence is sufficient to determine the effects of the preventive service on health outcomes, but confidence in the estimate } \\
\text { is constrained by such factors as } \\
\text { the number, size, or quality of individual studies. } \\
\text { inconsistency of findings across individual studies. } \\
\text { limited generalizability of findings to routine primary care practice. } \\
\text { lack of coherence in the chain of evidence. } \\
\text { As more information becomes available, the magnitude or direction of the observed effect could change, and this change may be large } \\
\text { enough to alter the conclusion. }\end{array}$ \\
\hline $\begin{array}{l}\text { The available evidence is insufficient to assess effects on health outcomes. Evidence is insufficient because of } \\
\text { the limited number or size of studies. } \\
\text { important flaws in study design or methods. } \\
\text { inconsistency of findings across individual studies. } \\
\text { gaps in the chain of evidence. } \\
\text { findings not generalizable to routine primary care practice. } \\
\text { lack of information on important health outcomes. } \\
\text { More information may allow estimation of effects on health outcomes. }\end{array}$ \\
Low
\end{tabular}

USPSTF indicates US Preventive Services Task Force.

HBV infection of 85.8 cases per 100000 deliveries from 1998 to 2011 (0.09\% of live-born singleton deliveries in the United States). ${ }^{1,2}$ Although there are guidelines for universal infant HBV vaccination, rates of maternal $\mathrm{HBV}$ infection have increased annually by $5.5 \%$ since 1998 . $^{1,2}$ Persons infected with HBV during infancy or childhood are more likely to develop chronic infection. Chronic HBV infection increases long-term morbidity and mortality by predisposing infected persons to cirrhosis of the liver and liver cancer.

\section{Reaffirmation}

In 2009, the USPSTF reviewed the evidence for screening for HBV infection in pregnant women and issued an A recommendation. ${ }^{3}$ The USPSTF has decided to use a reaffirmation deliberation process to update this recommendation. The USPSTF uses the reaffirmation process for well-established, evidence-based standards of practice in current primary care practice for which only a very high level of evidence would justify a change in the grade of the recommendation. ${ }^{4}$ In its deliberation of the evidence, the USPSTF 
Figure 2. Clinical Summary: Screening for Hepatitis B Virus Infection in Pregnant Women

\begin{tabular}{|l|l|}
\hline Population & Pregnant persons \\
\hline \multirow{2}{*}{ Recommendation } & Grade: A \\
& Screen for hepatitis B virus (HBV) infection. \\
\hline
\end{tabular}

\begin{tabular}{||l|l||}
\hline Risk Assessment & $\begin{array}{l}\text { In the United States, new cases of HBV among adults are largely transmitted through injection drug use or sexual intercourse, } \\
\text { but most prevalent cases of HBV infection are chronic infections from exposure occurring in infancy or childhood. Another major risk } \\
\text { factor for HBV infection is country of origin. In the United States, adults with HBV born in high-prevalence countries were commonly } \\
\text { infected during childhood. In children, the primary source of infection is perinatal transmission at birth. }\end{array}$ \\
\hline Screening Tests & $\begin{array}{l}\text { The principal screening test for detecting maternal HBV infection is the serologic identification of hepatitis B surface antigen (HBsAg). } \\
\text { Screening should be performed in each pregnancy, regardless of previous HBV vaccination or previous negative HBsAg test results. }\end{array}$ \\
\hline Screening Intervals & $\begin{array}{l}\text { A test for HBsAg should be ordered at the first prenatal visit. Women with unknown HBsAg status or with new or continuing risk factors } \\
\text { for HBV infection (eg, injection drug use or a sexually transmitted infection) should be screened at the time of admission to a hospital } \\
\text { or other delivery setting. }\end{array}$ \\
\hline $\begin{array}{l}\text { Treatment and } \\
\text { Interventions }\end{array}$ & $\begin{array}{l}\text { Interventions to prevent perinatal transmission of HBV infection include screening all pregnant women for HBV, vaccinating infants } \\
\text { born to HBV-negative mothers within } 24 \text { hours of birth, and completing the HBV vaccination series in infants by age 18 months. } \\
\text { For HBV-positive mothers, case management during pregnancy includes HBV DNA viral load testing and referral to specialty care for } \\
\text { counseling and medical management of HBV infection. For infants born to mothers who test positive for HBsAg, current guidelines for } \\
\text { case management include HBV vaccination and hepatitis B immune globulin (HBIG) prophylaxis within 12 hours of birth and completing } \\
\text { the vaccine series and serologic testing for infection and immunity at age } 9 \text { to } 12 \text { months. For infants born to mothers with unknown } \\
\text { HBsAg status, current guidelines for case management include HBV vaccination within } 12 \text { hours of birth, followed by HBIG prophylaxis. }\end{array}$ \\
\hline
\end{tabular}

For a summary of the evidence systematically reviewed in making this recommendation, the full recommendation statement, and supporting documents, please go to https://www.uspreventiveservicestaskforce.org.

considers whether the new evidence is of sufficient strength and quality to change its previous conclusions about the evidence.

\section{Detection}

The USPSTF previously reviewed the evidence on serologic testing for HBV (hepatitis B surface antigen [HBsAg]) in pregnancy and found adequate evidence of its accuracy (sensitivity and specificity both $>98 \%$ ).

\section{Benefits of Early Detection and Interventions}

The USPSTF found convincing evidence that universal prenatal screening for HBV infection substantially reduces perinatal transmission of HBV and the subsequent development of chronic HBV infection. The USPSTF found adequate evidence that vaccination of all infants against HBV infection and providing postexposure prophylaxis with hepatitis $B$ immune globulin (HBIG) at birth to infants of mothers infected with HBV substantially reduce the risk for acquisition of HBV infection in infants.

\section{Harms of Screening and Interventions}

The USPSTF found limited evidence on the harms of screening for HBV infection in pregnant women but bounded the potential harms of screening as no greater than small based on the high accuracy of screening and the low likelihood of harms from preventive interventions.

\section{USPSTF Assessment}

Using a reaffirmation process, the USPSTF concludes with high certainty that the net benefit of screening for HBV infection in pregnant women is substantial.

\section{Clinical Considerations}

Patient Population Under Consideration

This recommendation applies to all pregnant persons (Figure 2).

\section{Screening Tests}

The principal screening test for detecting maternal $\mathrm{HBV}$ infection is the serologic identification of $\mathrm{HBsAg}$. Screening should be performed in each pregnancy, regardless of previous HBV vaccination or previous negative $\mathrm{HBsAg}$ test results. ${ }^{1}$

\section{Screening Interval}

A test for HBsAg should be ordered at the first prenatal visit. Women with unknown HBsAg status or with new or continuing risk factors for HBV infection (eg, injection drug use or a sexually transmitted infection) should be screened at the time of admission to a hospital or other delivery setting. 
Treatment

Interventions to prevent perinatal transmission of HBV infection include screening all pregnant women for HBV followed by treatment, vaccinating infants born to HBV-negative mothers within 24 hours of birth, and completing the HBV vaccination series in infants by age 18 months. For HBV-positive mothers, case management during pregnancy includes HBV DNA viral load testing and referral to specialty care for counseling and medical management of HBV infection. For infants born to mothers who test positive for $\mathrm{HBsAg}$, current guidelines for case management include $\mathrm{HBV}$ vaccination and HBIG prophylaxis within 12 hours of birth and completing the vaccine series and serologic testing for infection and immunity at age 9 to 12 months. For infants born to mothers with unknown HBsAg status, current guidelines for case management include HBV vaccination within 12 hours of birth, followed by HBIG prophylaxis. ${ }^{5}$

Emerging evidence has demonstrated that administering tenofovir to HBV-positive women with acute infection significantly reduces the risk of $\mathrm{HBs} A g$ seropositivity in infants when combined with HBIG prophylaxis at birth and HBV vaccination. ${ }^{6,7}$ As a result, recent guidelines recommend testing for viral load, antiviral treatment, and HBV vaccination and HBIG prophylaxis. $^{5}$

\section{Useful Resources}

The USPSTF has made recommendations on screening for other infections, including chlamydia and gonorrhea, ${ }^{8} \mathrm{HBV}$ in nonpregnant adults and adolescents, ${ }^{9}$ genital herpes, ${ }^{10} \mathrm{HIV}_{1}{ }^{11}$ and syphilis in pregnant women. ${ }^{12}$

The Centers for Disease Control and Prevention (CDC) provides more information about $\mathrm{HBV}$ infection, including perinatal transmission. ${ }^{13,14}$

\section{Other Considerations}

\section{Implementation}

Universal screening for HBV infection in women during pregnancy is standard clinical practice in the United States. Presently, 26 states have laws mandating prenatal HBV screening. ${ }^{15}$ Although rates of maternal screening for HBV infection range from $84 \%$ to $88 \%$, screening rates during the first trimester are lower, with $60 \%$ of commercially insured and $39 \%$ of Medicaid-enrolled women screened during the first trimester. ${ }^{16}$ Seventy-one percent of infants receive HBV vaccination within 3 days of birth. ${ }^{1,17}$ Primary care clinicians and delivery settings must establish effective systems for the accurate and timely transfer of maternal HBsAg test results to labor, delivery, and newborn medical records to maximize benefit. ${ }^{1}$

\section{Research Needs and Gaps}

The USPSTF has identified areas of needed research. Continued research on effective implementation of case management in vulnerable populations most at risk for perinatal transmission of HBV infection is needed. Additional studies on the effectiveness of prenatal antiviral medication to reduce perinatal transmission are needed. Analyses of recent data from existing case management programs, such as the Perinatal Hepatitis B Prevention Program (PHBPP), would be helpful in understanding program performance and research needs. ${ }^{1}$ There is emerging evidence on the use of antiviral therapy during pregnancy. ${ }^{1,6,7}$ Further research is needed to examine the prevention of perinatal transmission.

\section{Discussion}

\section{Burden of Disease}

Hepatitis B is a viral infection of the liver transmitted through contact with the bodily fluids or blood of an infected individual. In the United States, prevalence estimates of chronic HBV infection range from approximately 850000 to more than 2 million cases. ${ }^{1,18-20}$ In the United States, new cases of HBV among adults are largely transmitted through injection drug use or sexual intercourse, but most prevalent cases of HBV infection are chronic infections from exposure occurring in infancy or childhood. Another major risk factor for HBV infection is country of origin. In the United States, adults with HBV born in high-prevalence countries were commonly infected during birth. ${ }^{19}$ In US-born children, the primary source of infection is vertical transmission at birth. ${ }^{21}$ According to the CDC, 800 to 1000 cases of perinatal transmission ( $3.8 \%$ of infants born to HBV-positive women) occurred yearly from 2000 to $2009 .^{22}$

Since 1998, rates of maternal HBV infection have increased annually by $5.5 \% .{ }^{1,2}$ Older maternal age, race/ethnicity (non-Hispanic black and Asian populations), lower education, higher poverty levels, and lack of insurance coverage are risk factors for HBV infection among women. ${ }^{2,23}$

Persons infected with HBV during infancy or childhood are more likely to develop chronic HBV infection and have poor long-term health outcomes (eg, chronic hepatitis, cirrhosis, or hepatocellular carcinoma) compared with persons infected later in life. ${ }^{1}$ Acute HBV infections progress to chronic disease in $80 \%$ to $90 \%$ of infected infants, $30 \%$ of acute infections progress before age 6 years, and less than $1 \%$ to $12 \%$ of acute infections progress in older children or adults. Approximately $25 \%$ of persons who become chronically infected during childhood and $15 \%$ of those infected as adults will die of cirrhosis or hepatocellular carcinoma. ${ }^{1,5,24}$

\section{Scope of Review}

To reaffirm its 2009 recommendation on screening for HBV infection in pregnant women, the USPSTF commissioned a reaffirmation evidence update. The aim of this update is to identify substantial new evidence sufficient enough to change the prior recommendation. Case management is the standard intervention in the United States for all HBV-positive pregnant women. As a result, the USPSTF targeted its evidence review to focus on the effectiveness and potential harms of screening and the effectiveness and harms of case management to prevent perinatal transmission. ${ }^{25}$

Accuracy of Screening Tests

The primary screening test for detecting maternal HBV infection is the serologic detection of HBsAg. Serologic immunoassays for detecting HBsAg have a reported sensitivity and specificity greater than $98 \%{ }^{26,27}$

\section{Effectiveness of Early Detection and Treatment}

No studies were identified that directly assessed the benefits or harms of universal HBV screening during pregnancy. Two fairquality observational studies reported perinatal transmission rates (primary outcome) over time.,28,29 
One study reported outcomes of case management from 1994 to 2008 for 155081 infants born to HBV-positive women in the national PHBPP, administered by the CDC. ${ }^{1,28}$ From 1994 to 2008 , the estimated number of infants born to HBV-positive women increased in the United States from 19208 to $25600(P<.001)$. The proportion of infants born to HBV-positive women enrolled in the PHBPP for case management also increased during this period, from $42.1 \%$ to $47.9 \%(P=.002)$. The number of infants receiving case management increased from 7415 in 1994 to 12033 in $2008(P<.001){ }^{1,28}$

Perinatal transmission outcomes were reported for infants born from 1999 to 2008 who received serologic testing ( $n=55362$ ). There was a statistically significant decrease in the perinatal transmission rate $(P=.001)$. In 1999, $1.9 \%$ of infants who received serologic testing were infected with HBV; by 2008 , the rate had decreased to $0.8 \%(P=.001){ }^{1,28}$

The second observational study was conducted in a large regional health care system in the United States (Kaiser Permanente Northern California). ${ }^{129}$ The case management program reported on 4446 infants born to HBV-positive women from 1997 to 2010 . More than $97 \%$ of the infants received HBV vaccination and HBIG prophylaxis within 12 hours of birth. Overall rates of perinatal transmission were very low $(0.75 \%)$, and a decreasing trend in perinatal transmission was reported (incidence rate ratio, 0.90 [95\% Cl, 0.82-1.00]) ${ }^{1,29}$

The results on historical trends from the observational studies are at risk of bias because of changes in case management program implementation, other interventions (eg, antiviral medication), cultural or secular changes (eg, universal vaccination), changes in reporting methods, and differences in data collection procedures. ${ }^{1}$

\section{Potential Harms of Screening and Treatment}

No studies were identified that reported the potential harms of universal HBV screening during pregnancy or case management. Screening has a low false-positive rate, and treatment is rarely harmful. ${ }^{1}$

\section{Estimate of Magnitude of Net Benefit}

The USPSTF considered the evidence using a reaffirmation process. The USPSTF previously found adequate evidence that serologic testing for HBsAg accurately identifies HBV infection. Interventions are effective for preventing perinatal transmission, based on foundational evidence and observational studies of US case management programs. In addition, there is evidence that over time, perinatal transmission has decreased among women and infants enrolled in case management, providing an overall substantial health benefit. Therefore, the USPSTF reaffirms its previous conclusion that there is convincing evidence that screening for HBV infection in pregnant women provides substantial benefit.

\section{Response to Public Comment}

Adraft version of this recommendation statement was posted for public comment on the USPSTF website from January 8, 2019, to February 4,2019 . A majority of the comments wanted more information about treatment with antiviral therapy. In response, the USPSTF added information about emerging evidence that treatment with antiviral therapy works and that more research is needed in the Clinical Considerations and Research Needs and Gaps sections.

\section{Reaffirmation of Previous USPSTF Recommendation}

This recommendation is a reaffirmation of the USPSTF 2009 recommendation statement. In 2009, the USPSTF reviewed the evidence for screening for $\mathrm{HBV}$ infection in pregnant women and found that the benefits of screening substantially outweighed the harms. ${ }^{3}$ For the current recommendation, the USPSTF commissioned a targeted review to look for new and substantial evidence on the benefits and harms of screening and determined that the net benefit of screening for HBV infection in pregnant women continues to be well established. The USPSTF found no new substantial evidence that would change its recommendation and, therefore, reaffirms its recommendation to screen for HBV infection in pregnant women.

\section{Recommendations of Others}

The American College of Obstetricians and Gynecologists recommends screening for $\mathrm{HBV}$ with serologic testing for HBsAg in every pregnant patient at the earliest prenatal visit. These tests should be designated as "prenatal." Pregnant women who test positive for HBsAg should then be tested for HBV DNA. ${ }^{30}$ The CDC Advisory Committee on Immunization Practices similarly recommends testing for HBsAg in all pregnant women during an early prenatal visit (eg, in the first trimester) and HBV DNA testing for pregnant women who test positive for HBsAg. ${ }^{5}$ The American Academy of Family Physicians recommends screening for $\mathrm{HBV}$ infection in pregnant women at their first prenatal visit. ${ }^{31}$ The American Association for the Study of Liver Diseases recommends screening in all pregnant women by testing for HBsAg and the hepatitis B surface antibody (anti-HBs). ${ }^{24}$

\section{ARTICLE INFORMATION}

Accepted for Publication: June 13, 2019.

The US Preventive Services Task Force (USPSTF) members: Douglas K. Owens, MD, MS; Karina W. Davidson, PhD, MASc; Alex H. Krist, MD, MPH; Michael J. Barry, MD; Michael Cabana, MD, MA, $\mathrm{MPH}$; Aaron B. Caughey, MD, PhD; Chyke A. Doubeni, MD, MPH; John W. Epling Jr, MD, MSEd; Alex R. Kemper, MD, MPH, MS; Martha Kubik, PhD, RN; C. Seth Landefeld, MD; Carol M. Mangione, MD, MSPH; Lori Pbert, PhD; Michael Silverstein, MD, MPH; Melissa A. Simon, MD, MPH; Chien-Wen Tseng, MD, MPH, MSEE; John B. Wong, MD.

\begin{abstract}
Affiliations of The US Preventive Services Task Force (USPSTF) members: Veterans Affairs Palo Alto Health Care System, Palo Alto, California (Owens); Stanford University, Stanford, California (Owens); Feinstein Institute for Medical Research at Northwell Health, Manhasset, New York (Davidson); Fairfax Family Practice Residency, Fairfax, Virginia (Krist); Virginia Commonwealth University, Richmond (Krist); Harvard Medical School, Boston, Massachusetts (Barry); University of California, San Francisco (Cabana); Oregon Health \& Science University, Portland (Caughey); Mayo Clinic, Rochester, New York (Doubeni); Virginia Tech Carilion School of Medicine, Roanoke (Epling Jr); Nationwide Children's
\end{abstract}

Hospital, Columbus, Ohio (Kemper); Temple University, Philadelphia, Pennsylvania (Kubik); University of Alabama at Birmingham (Landefeld); University of California, Los Angeles (Mangione); University of Massachusetts Medical School, Worcester (Pbert); Boston University, Boston, Massachusetts (Silverstein); Northwestern University, Evanston, Illinois (Simon); University of Hawaii, Honolulu (Tseng); Pacific Health Research and Education Institute, Honolulu, Hawaii (Tseng); Tufts University, Medford, Massachusetts (Wong).

Correction: This article was corrected on September 17, 2019, for incorrect language in the text and Figure 2. 
Author Contributions: Dr Owens had full access to all of the data in the study and takes responsibility for the integrity of the data and the accuracy of the data analysis. The USPSTF members contributed equally to the recommendation statement.

Conflict of Interest Disclosures: All authors have completed and submitted the ICMJE Form for Disclosure of Potential Conflicts of Interest. Authors followed the policy regarding conflicts of interest described at https://www.

uspreventiveservicestaskforce.org/Page/Name/ conflict-of-interest-disclosures. All members of the USPSTF receive travel reimbursement and an honorarium for participating in USPSTF meetings. Dr Barry reported receiving grants and personal fees from Healthwise (a nonprofit), outside the submitted work. Dr Doubeni reported receiving personal fees from UpToDate, outside the submitted work. Dr Wong reported that he participated in the American Association for the Study of Liver Diseases' Hepatitis B Guidance and Hepatitis B Systematic Review Group and contributed to the group's hepatitis B guidelines. No other disclosures were reported.

Funding/Support: The USPSTF is an independent, voluntary body. The US Congress mandates that the Agency for Healthcare Research and Quality (AHRQ) support the operations of the USPSTF.

Role of the Funder/Sponsor: AHRQ staff assisted in the following: development and review of the research plan, commission of the systematic evidence review from an Evidence-based Practice Center, coordination of expert review and public comment of the draft evidence report and draft recommendation statement, and the writing and preparation of the final recommendation statement and its submission for publication. AHRQ staff had no role in the approval of the final recommendation statement or the decision to submit for publication.

Disclaimer: Recommendations made by the USPSTF are independent of the US government. They should not be construed as an official position of AHRQ or the US Department of Health and Human Services.

Additional Contributions: We thank Iris Mabry-Hernandez, MD, MPH (AHRQ), who contributed to the writing of the manuscript, and Lisa Nicolella, MA (AHRQ), who assisted with coordination and editing.

\section{REFERENCES}

1. Henderson JT, Webber EM, Bean SI. Screening for Hepatitis B Virus Infection in Pregnant Women: An Updated Systematic Review for the US Preventive Services Task Force: Evidence Synthesis No. 179. Rockville, MD: Agency for Healthcare Research and Quality; 2019. AHRQ publication 19-05248-EF-1.

2. Salemi JL, Spooner KK, Mejia de Grubb MC, Aggarwal A, Matas JL, Salihu HM. National trends of hepatitis $B$ and $C$ during pregnancy across sociodemographic, behavioral, and clinical factors, United States, 1998-2011. J Med Virol. 2017;89(6): 1025-1032. doi:10.1002/jmv.24725

3. U.S. Preventive Services Task Force. Screening for hepatitis B virus infection in pregnancy: U.S. Preventive Services Task Force reaffirmation recommendation statement. Ann Intern Med. 2009;150(12):869-873. doi:10.7326/ 0003-4819-150-12-200906160-00011

4. US Preventive Services Task Force (USPSTF). Procedure Manual. USPSTF website. https://www.uspreventiveservicestaskforce.org/ Page/Name/procedure-manual. 2018. Accessed May 28, 2019.

5. Schillie S, Vellozzi C, Reingold A, et al. Prevention of hepatitis $B$ virus infection in the United States: recommendations of the Advisory Committee on Immunization Practices. MMWR Recomm Rep. 2018;67(1):1-31. doi:10.15585/mmwr.rr6701a1

6. Hyun MH, Lee YS, Kim JH, et al. Systematic review with meta-analysis: the efficacy and safety of tenofovir to prevent mother-to-child transmission of hepatitis B virus. Aliment Pharmacol Ther. 2017;45(12):1493-1505. doi:10.1111/apt.14068

7. Brown RS Jr, McMahon BJ, Lok AS, et al. Antiviral therapy in chronic hepatitis $B$ viral infection during pregnancy: a systematic review and meta-analysis. Hepatology. 2016;63(1):319-333. doi:10.1002/hep. 28302

8. LeFevre ML; U.S. Preventive Services Task Force. Screening for chlamydia and gonorrhea: U.S Preventive Services Task Force recommendation statement. Ann Intern Med. 2014;161(12):902-910. doi:10.7326/M14-198

9. LeFevre ML; U.S. Preventive Services Task Force. Screening for hepatitis B virus infection in nonpregnant adolescents and adults: U.S. Preventive Services Task Force recommendation statement. Ann Intern Med. 2014;161(1):58-66. doi: 10.7326/M14-1018

10. Bibbins-Domingo K, Grossman DC, Curry SJ, et al; US Preventive Services Task Force. Serologic screening for genital herpes infection: US Preventive Services Task Force recommendation statement. JAMA. 2016;316(23):2525-2530. doi:10 1001/jama.2016.16776

11. Moyer VA; U.S. Preventive Services Task Force. Screening for HIV: U.S. Preventive Services Task Force recommendation statement. Ann Intern Med. 2013;159(1):51-60. doi:10.7326/0003-4819-159-1. 201307020-00645

12. Curry SJ, Krist AH, Owens DK, et al; US Preventive Services Task Force. Screening for syphilis infection in pregnant women: US Preventive Services Task Force reaffirmation recommendation statement. JAMA. 2018;320(9): 911-917. doi:10.1001/jama.2018.11785

13. Centers for Disease Control and Prevention (CDC). Viral hepatitis: perinatal transmission. CDC website. https://www.cdc.gov/hepatitis/hbv/ perinatalxmtn.htm. 2018. Accessed May 28, 2019.

14. Centers for Disease Control and Prevention (CDC). Hepatitis B information. CDC website. https://www.cdc.gov/hepatitis/hbv/index.htm. 2019. Accessed May 28, 2019

15. Culp LA, Caucci L, Fenlon NE, Lindley MC, Nelson NP, Murphy TV. Assessment of state perinatal hepatitis B prevention laws. Am J Prev Med. 2016;51(6):e179-e185. doi:10.1016/j.amepre.2016. 09.005

16. Kolasa MS, Tsai Y, Xu J, Fenlon N, Schillie S. Hepatitis B surface antigen testing among pregnant women, United States 2014. Pediatr Infect Dis J. 2017:36(7):e175-e180. doi:10.1097/INF. 0000000000001516

17. Hill HA, Elam-Evans LD, Yankey D, Singleton JA Kang Y. Vaccination coverage among children aged 19-35 months-United States, 2016. MMWR Morb Mortal Wkly Rep. 2017;66(43):1171-1177. doi:10. 15585/mmwr.mm6643a3
18. Roberts H, Kruszon-Moran D, Ly KN, et al. Prevalence of chronic hepatitis B virus (HBV) infection in U.S. households: National Health and Nutrition Examination Survey (NHANES), 1988-2012. Hepatology. 2016;63(2):388-397. doi: 10.1002/hep.28109

19. Kowdley KV, Wang CC, Welch S, Roberts $\mathrm{H}$, Brosgart CL. Prevalence of chronic hepatitis B among foreign-born persons living in the United States by country of origin. Hepatology. 2012;56(2): 422-433. doi:10.1002/hep.24804

20. Gish RG, Sollano JD Jr, Lapasaran A, Ong JP. Chronic hepatitis B virus in the Philippines. J Gastroenterol Hepatol. 2016;31(5):945-952. doi: 10.1111/jgh.13258

21. Dionne-Odom J, Tita AT, Silverman NS; Society for Maternal-Fetal Medicine (SMFM). \#38: Hepatitis $B$ in pregnancy screening, treatment, and prevention of vertical transmission. Am J Obstet Gynecol. 2016;214(1):6-14. doi:10.1016/j.ajog.2015. 09.100

22. Ko SC, Fan L, Smith EA, Fenlon N, Koneru AK, Murphy TV. Estimated annual perinatal hepatitis B virus infections in the United States, 2000-2009. J Pediatric Infect Dis Soc. 2016;5(2):114-121. doi:10. 1093/jpids/piu115

23. Miller GK, Barker L, Taylor A, et al. Hepatitis B vaccination among US women of reproductive age. $J$ Womens Health (Larchmt). 2017;26(4):A29.

24. Terrault NA, Lok ASF, McMahon BJ, et al. Update on prevention, diagnosis, and treatment of chronic hepatitis B: AASLD 2018 hepatitis B guidance. Hepatology. 2018;67(4):1560-1599. doi: 10.1002/hep.29800

25. Henderson JT, Webber EM, Bean SI. Screening for hepatitis B infection in pregnant women: updated evidence report and systematic review for the US Preventive Services Task Force [published July 23, 2019]. JAMA. doi:10.1001/jama.2019.9365

26. Centers for Disease Control and Prevention (CDC). Sensitivity of the test for antibody to hepatitis B surface antigen-United States. MMWR Morb Mortal Wkly Rep. 1993;42(36):707-710

27. World Health Organization. Hepatitis B Surface Antigen Assays: Operational Characteristics (Phase I). Geneva, Switzerland: World Health Organization; 2001.

28. Smith EA, Jacques-Carroll L, Walker TY, Sirotkin B. Murphy TV. The national Perinatal Hepatitis B Prevention Program, 1994-2008. Pediatrics. 2012; 129(4):609-616. doi:10.1542/peds.2011-2866

29. Kubo A, Shlager L, Marks AR, et al. Prevention of vertical transmission of hepatitis $B$ : an observational study. Ann Intern Med. 2014;160(12) 828-835 doi:10.7326/M13-2529

30. American College of Obstetricians and Gynecologists. ACOG Practice Bulletin No. 86: viral hepatitis in pregnancy. Obstet Gynecol. 2007;110 (4):941-956. doi:10.1097/01.AOG.0000263930. 28382.2a

31. American Academy of Family Physicians (AAFP). Clinical preventive service recommendation: hepatitis. AAFP website. https://www.aafp.org/patient-care/clinicalrecommendations/all/hepatitis.html. Accessed May 28,2019 